Tarih Kültür ve Sanat Araştırmaları Dergisi

Revue des Recherches en Histoire Culture et Art

مجلة البحوث التاريخية و الثقافية و الفنية
Vol. 7, No. 3, September 2018

Copyright (C) Karabuk University

http://kutaksam.karabuk.edu.tr

\title{
DOI: 10.7596/taksad.v7i3.1558
}

Citation: Moghanipoor, M., Zafarmand, S., \& Rahmani, A. (2018). Study of Mutual Effects of Neyshabur and Changsha Ceramics During the Abbasid Era (750- 1258 AD). Journal of History Culture and Art Research, 7(3), 187-198. doi:http://dx.doi.org/10.7596/taksad.v7i3.1558

\section{Study of Mutual Effects of Neyshabur and Changsha Ceramics During the Abbasid $\operatorname{Era~(750-1258~AD)~}$}

\author{
Majid Reza Moghanipuor*1, Seyed Javad Zafarmand², Ashkan Rahmani ${ }^{3}$
}

\begin{abstract}
Located in northeast of Iran, Neyshabur was one of the most prolific centers through the Abbasids (750 1258 AD). The center was at its peak until the invasion of the Mongols (1258 AD) to Iran. Neyshabur's location in the course of the Silk Road, made possible the especial opportunity of the west range of cultural inter- notation with other cultural centers. Hence the artifacts of Neyshabur were partly - mostly in technical and structural respect- inspired by the eastern civilizations, namely China, and on the other side in design and idea mostly depended on the Abbasid Khalifa-Emperor capitals. The present article is a comparative study of the mutual effects and interactions between Abbasid Neyshabur and Chinese ceramics, mostly produced in Changsha region, both at the eve of prolificacy, supposed that the Neyshabur products were directly inspired by the Changsha, one of the most developed centers for producing glazed ceramics. The study was formed on four major variables; form, technique, function and ornaments. The results of the study showed that there are major identical properties technique and function in both collection, and the most significant differences can be found in the types and high quality of the ornaments and decoration in Neyshabur products. Respectively, these types and styles of decoration especially in composition strategies for occupied and empty spaces in the designs of Changsha ceramics, were mostly inspired by the Neyshabur products. The results also showed that the differences could be refereed to different pictorial motifs and designs of the two regions, and attitudes of the producers, in other words, based on the defined aims, the Changsha ceramics were meant for mass production with definite commercial and economic intention in relation to other cultural centers. In contrast, the Neyshabur ceramics were intended for a more limited range of audience, which due to the more restricted variety of themes and decoration designs were produced for specific orders.
\end{abstract}

Keywords: Changsha kiln, Neyshabur, Maritime silk road, Abbasid.

\footnotetext{
${ }^{1}$ Corresponding author. Assist. Prof. Dr., Department of Art, Faculty of Art \& Architecture, Shiraz University, Iran. E-mail: moghanipour@shirazu.ac.ir

2 Assoc. Prof. Dr., Department of Art, Faculty of Art \& Architecture, Shiraz University, Iran. E-mail: szafarmand@gmail.com

3 Assist. Prof. Dr., Department of Art, Faculty of Art \& Architecture, Shiraz University, Iran. E-mail: rahmani.ashkan@shirazu.ac.ir
} 


\section{Introduction}

Although Neyshabur in north-east of Iran and Changsha in south-west China were active in the production of ceramic products through the Abbasid period (750-1258 AD), Changsha had an older history of producing ceramics. Neyshabur was a thriving commercial city in that period that was connected to the Eastern territories on one side, and the port cities and also the Islamic Khalifa-living capitals on the other ${ }^{4}$ (Chakanagi et al., 1996; Wood, 2002).

Also the geographical location of Changsha provided access to the Maritime Silk Road; therefore, many Changsha kiln products were exported to foreign countries through Maritime silk road.

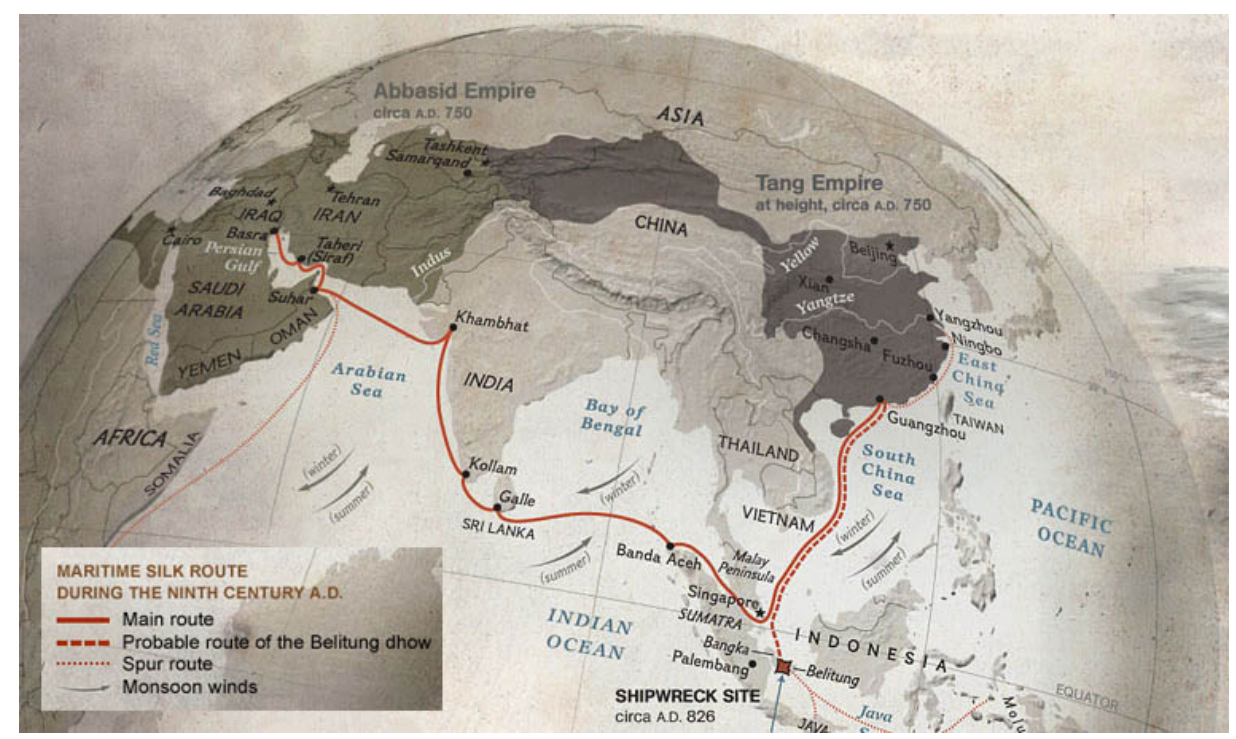

Figure 1. Maritime Silk Road during the ninth Century A.D. (Part of the map) (http://ngm.nationalgeographic.com, 19 May 2015)

This article seeks evidence to prove the effectiveness of methods of making and decorating ceramic products in Changsha on Neyshabur's products. The research method is descriptive-analytic and basically qualitative. In it, through comparative tables, similarities of the artifact forms and production techniques in Changsha and Neyshabur regions will be extracted and analyzed.

In this article, having introduced a historical description of Neyshabur, the clays and ceramics will be presented in the tables based on the Wilkinson's categorization. Afterwards, the Changsha ceramics and porcelains with similarities in form, technique and ornament with Neyshaburs' clays and ceramics are described and categorized (with regard to the evidence found in the Wrecked Ship etc). According to the similarities in both regions, we will in the end analyze the influence of Neyshabur products from Tang artifacts of Changsha. We will also discuss reasons for the differences, in spite of the similarities in some aspects.

\section{Neyshabur and its Ceramics}

The city of Neyshabur was founded by order of the Sasanid king Shapoor I as a military base for the wars of eastern fronts (in the mid-decades of the third century). It was conquered by Muslims in 436 A.D. during the reign of Omar (Bulliet, 1973). Because of its pleasant climate and ideal conditions for migration, many Arabs immigrated there during the early centuries of Islam (Ettinghausen, 1981). Some movements against

\footnotetext{
${ }^{4}$ Cities such as Siraf, Moosel, Baghdad etc were connected to the south-east coast of China through the Maritime silk road.
} 
Omavid and Abbasid governments were also formed in Neyshabur (Ettinghausen, 1981; Karimi \& Kiani, 1985). Samanid era (874-1000AD) is known as the most important period in Neyshabur's artistic promotion (Rafii, 1999). Its ceramics are known as early-Islamic-period in historical categorization. From 1935 to 1940, excavations were done in the historical hills of Neyshabur by the Iranology team of Metropolitan Museum of New York City to discover elements and signs of Sasanid era. Instead, they found many pieces of ceramics belonging to the Islamic period (Ghouchani, 1986). A thorough description of the Metropolitan museum discoveries were studied in a book called "Neyshabur, the Early Islamic Period Porcelain" published by Wilkinson (1974). In the 1988 discoveries of ceramic and porcelain furnaces, it was also specified that Neyshabur was one of the most important epicenters of ceramic production from the $9^{\text {th }}$ to $12^{\text {th }}$ centuries, most of which belonged to the reign of Samanid, in $9^{\text {th }}$ and $10^{\text {th }}$ centuries. As a result, they are also known as Samanid ceramics (Wilkinson, 1973).

The excavated items found in this region consisted of a variety of glazed and non-glazed vases/dishes; their variety included the form, use, ornament techniques, type of ornamental pictures, choice of colors, etc. Wilkinson has placed them in twelve categories. One of the important features of the categorized pieces is the ceramics from China (Tang period):

Table 1. A variety of technical ceramics in Neyshabur, Based on the Wilkinson's categorization (Rafii, 1999; http://en.Wikipedia.org)

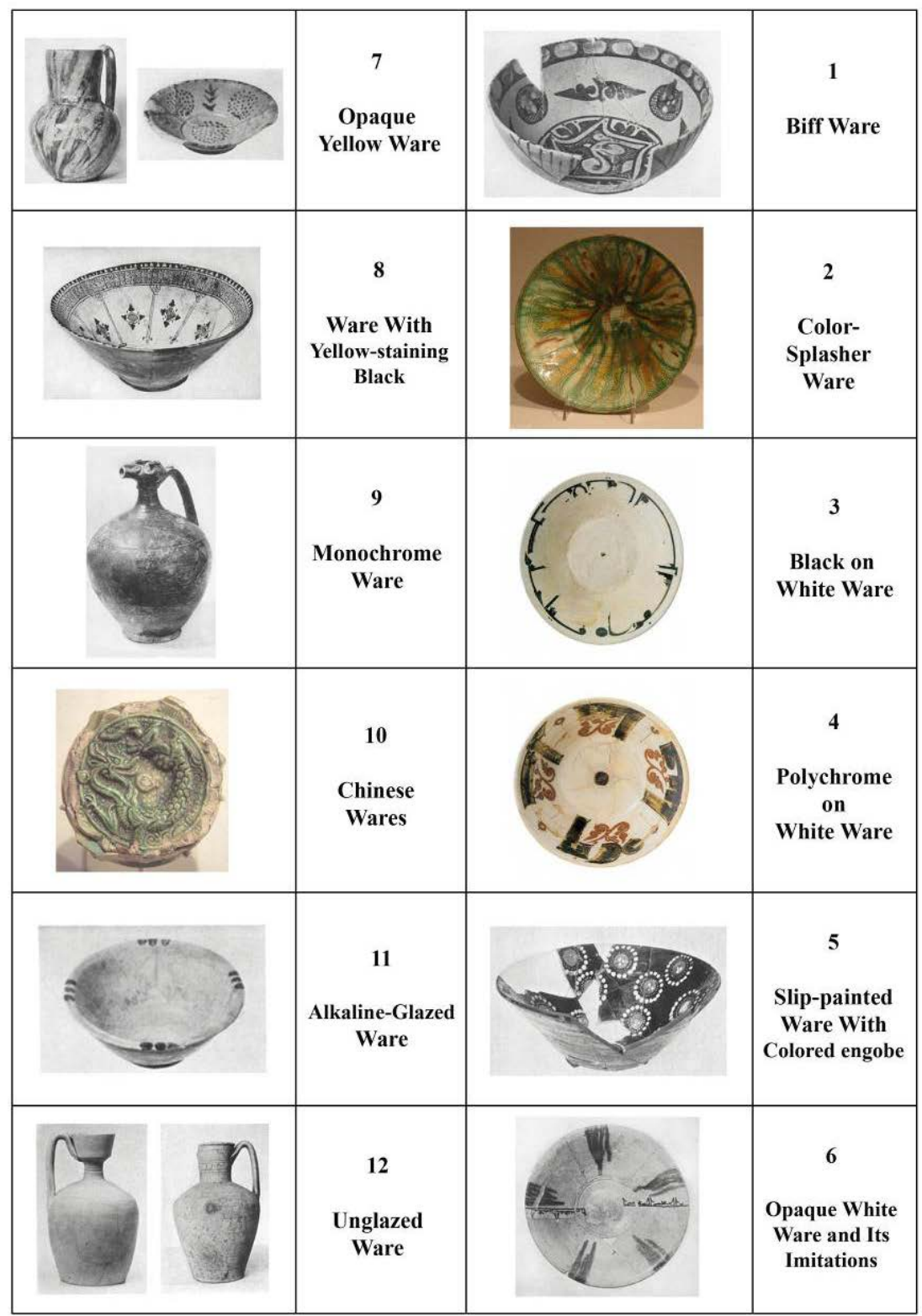


Table 2. Pottery decoration of Neyshabur (Rafii, 1999; Wilkinson, 1973)

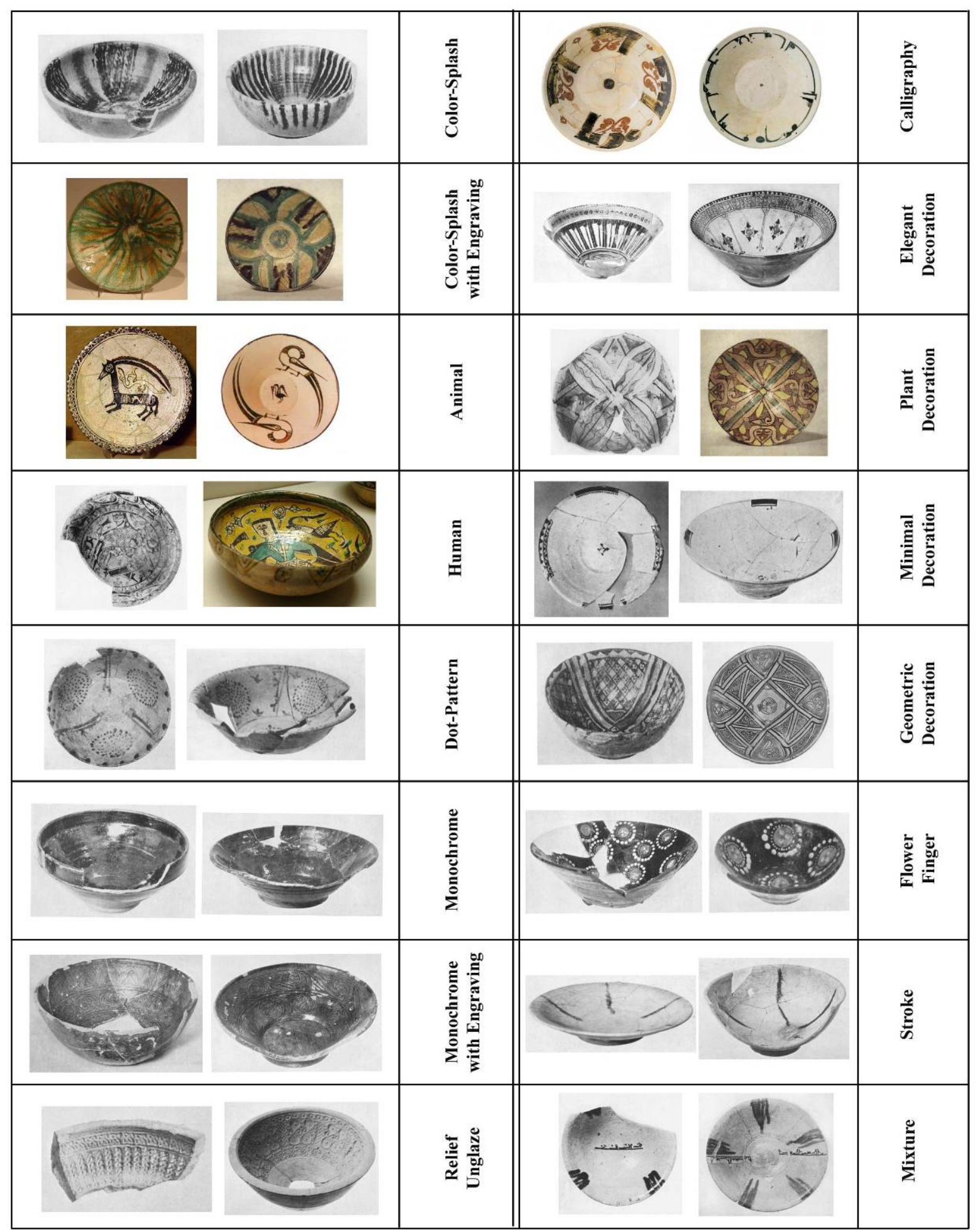

\section{Tang Dynasty Changsha Kiln Ceramics}

Most of the information collected on ceramic industry in Changsha region in Tang era was gained through the discovery of the party of goods in a ship wreckage; the excavated artifacts from the wreckage exceeds 
the whole artifacts primarily gained from the region in quantity. The study of the artifacts from these two sources and other regions which had trade with China gives a rather clear perspective of properties of the productions from Changsha at its peak.

Evidence from the field surveys has also allowed archaeologists to outline the history of ceramic manufacture in Changsha. They created a four-part per iodization from the kilns' early development to their heyday - dating from the High Tang (mid-eighth century) to the Five Dynasties periods:

Period 1 dates from the late High Tang to mid-Tang (760s-780s). Monochrome, green-tinged glazed wares dominated this period. Under-glaze colored decoration and molded appliqué on objects such as ewers were found only occasionally; no wares with white glaze and green color decoration were found whatsoever.

Period 2 is equivalent to the end of the mid-Tang and beginning of the late Tang, corresponding to the first half of the ninth century. The characteristic Changsha products with colored under-glaze gradually became prolific during this period. Large numbers of ewers with a spout and handle and decorated with appliquéd dark brown patches appeared.

Period 3 is equated with the late Tang, in the second half of the ninth century. This period marked the height of Changsha's productive prosperity and prestige, when wares with color under-glaze decoration predominated. In addition, many works marked with inscriptions have been found from this period.

In Period 4, contemporary with the very end of the Tang and beginning of the Five Dynasties period, Changsha ware remained one of the three major ceramic exports, along with Yue ware and Ding whiteglazed ware. But though colored under-glaze decoration was still mainstream and its manufacture continued to thrive, there were signs that the quality of Changsha wares' body, glaze, and decoration had slipped (Yang, 2011: 155-158).

Ceramic ware manufactured in Changsha kilns during the Tang dynasty varied greatly in form. Chinese archaeologists have distinguished about seventy different product forms. They can be divided into ten core groups, including ewers and vases, bowls and saucer dishes, jars, basins and washers, boxes, lamps, tools such as milling stones and milling blocks, objects for the scholar's desk, pillows, and others (Yang, 2011: 158).

Almost all the artifacts produced in Changsha were among the items discovered in the shipwreck, out of which drinking utensils, plates and saucers prove to be more significant, either in quality and quantity.

Like all other southern ceramics, Changsha ceramics from the Belitung wreck were made of siliceous stoneware and were rich in fine quartz. Their bodies were slightly coarse; gray, grayish white, or slightly reddish-white; and contained sand particles. To reduce the need for excessive glazing-as well as to brighten the color-white or off-white slip was applied to the body of a vessel before any decoration and glaze was applied, thereby making the glaze more adhesive. This process was used with almost all shapes and types of ceramics with various glazes and colored under- glaze decorations (Yang, 2011).

Because Changsha bowls and plates have the closest compatibility with those of Neyshabur, wed focus on the description and ornaments of these dishes. The colors applied in Changsha plates and bowls are mostly green (produced from copper) and brown (produced from iron). Both colors undergo some changes affected by transparent glaze and the result would be a darker brown and a lighter green. Brown was often used for decorating the margins of the dishes. One of the simple and routine ornaments of Changsha plates has been the drawing of four triangular shapes in the corner of the plate so that there would be a squareshaped space in the center, later applied as a decorative frame.

Similar to the Tangs and ewer, Ornamental reliefs' themes in the bowls and plates produced in Changsha, included a wide range of variety such as plants, flowers, steam or twisted clouds, scenery, birds, line and 
fish. The style of presenting such themes seemed to be free and yet professional, inspired by Kuangcao, a wild cursive line, a favorite style in Changsha. Although the development of Changsha decreased the use of traditional themes, the representing style of forms and themes were still under the influence of powerful eastern traditions. The most significant ornamental reliefs applied in the plates produced in Changsha are shown in the table below:

Table 3. A variety of ceramic decoration in Changsha (Krahl, 2011; http://newsilkroadevent.com/en/changsha-kiln)

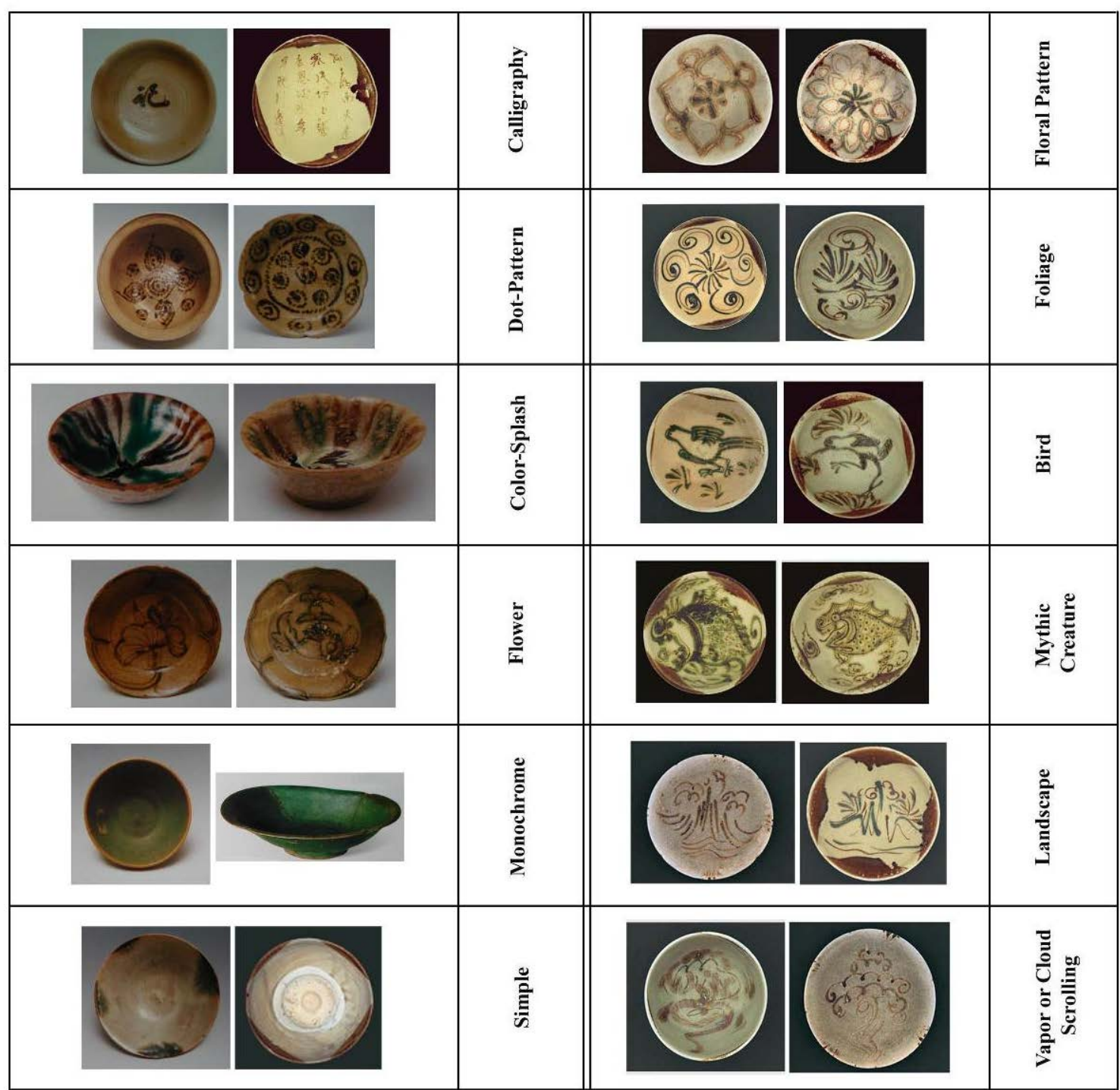

\section{A Comparative Study of Changsha products and Neyshabur}

Having introduced the ceramic products of the two regions in Iran and China, the comparative study of the similarities between the products of the regions will be presented through comparative tables to prove the influence of Changsha products on Neyshabur. 
Table 4. Similar founds in Changsha products and Neyshabur

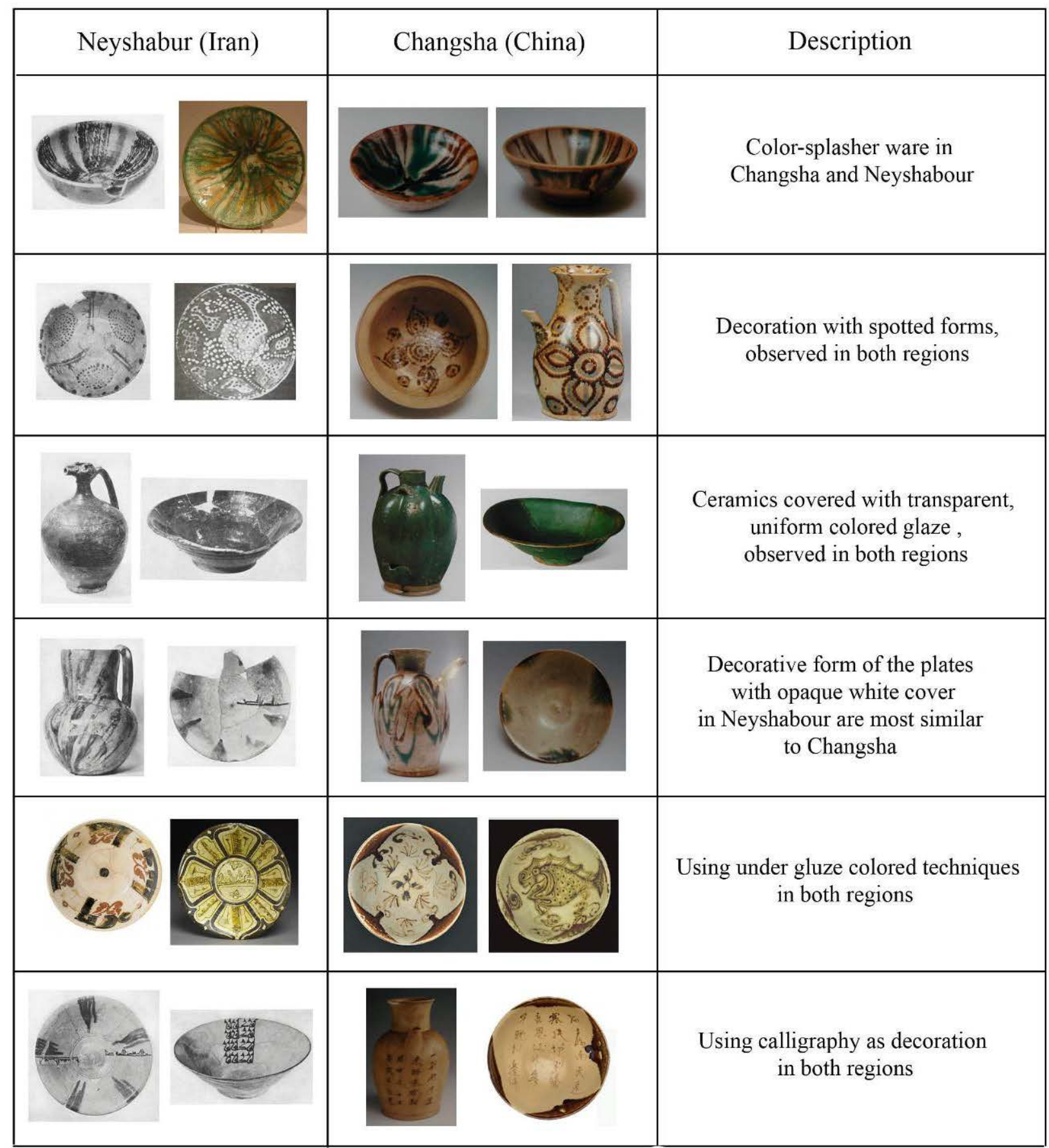

\section{Data Analysis}

Regarding Neyshabur's 12-class category of products presented by Wilkinson; there are similarities in form and ornamental technique in both regions. Similarities in form, ornamental technique and in some cases their colors could be taken as evidence that Neyshaburs' manufactories' recognized Changsha products and selected such style as a ready-decoration technique; this is compatible with the flourishing periods of pottery in each region (Changsha 750-907, Neyshabur 800-1000). The most important similarities are as followed: 
- Applied form and technique in plates with besprent glaze (second class of the Wilkinson category) are quite similar in some cases to Changsha products.

- Decoration with spotted forms is found in both regions.

- Ceramics covered with transparent, uniform colored glaze (especially with green) are among the decorations common to both Neyshabur and Changsha.

- Decorative forms of the plates with opaque white cover in Neyshabur (sixth class of Wilkinson categorization) are quite similar to Changsha decorations.

In the $9^{\text {th }}$ century specifically, Iranian potters imitated some far-eastern ceramics among which was a kind with a cover of colored glazes quite common in China during Tang era (Towhidi, 1999; Kambakhsh, 2001). Although Iranians had abundantly applied colored-glaze in their ancient works, there were no samples of ceramics with the multi-color technique and the transparent glaze cover during the first centuries of Islamic period. Apparently, Neyshabur producers adopted Chinese works belonging to Tang era as their technical patterns for producing their containers (Wilkinson, 1973: 158-178).

Studying Iranian ceramics or even ceramics belonging to the Islamic era reveals that the application of handwriting as a common ornamental element is not detected prior to Neyshabur. The themes are adopted from thoughts and beliefs of the two societies. However, there is a huge difference between the Chinese cursive and Kufi writings in Neyshabur works. In "China and the Arts of Islam", Mohammad Hassan Zaki has mentioned the significance of the aesthetics of handwriting for the Chinese and Muslims, along with the influence of Chinese calligraphy on Kufi handwriting (Hasan, 2005).

In addition to the above-mentioned points, during the categorization of what was discovered in Neyshabur, Wilkinson ascribes the production of some of the ceramics to China (Tang age) (Wilkinson, 1973: 254-258). One such piece, presented in Wilkinson's book, is precisely similar to the Tangs' with relief ornaments and partial glaze, which was vastly in production in Changsha. This piece is the connecting joint of the handle to the body of a drinking utensil which had engraved reliefs and patterns covered with transparent colored glaze. Other pieces of this collection also have similarities with Changsha products in their form and technique.

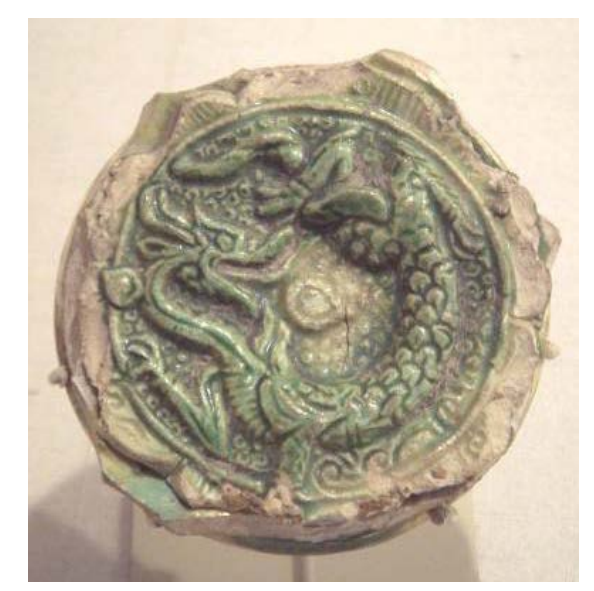

Figure 2. Chinese pottery from the Tang period; Found in Neyshabur (http://en.wikipedia.org) 


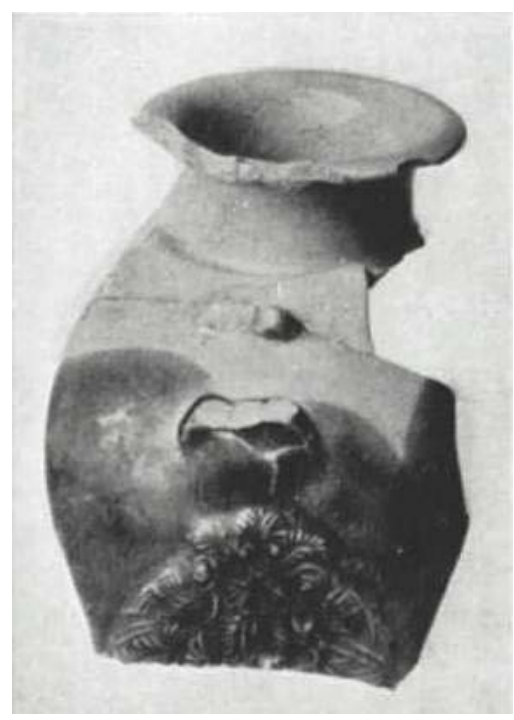

Figure 3. Chinese pottery from the Tang period; Found in Neyshabur (Wilkinson, 1973).
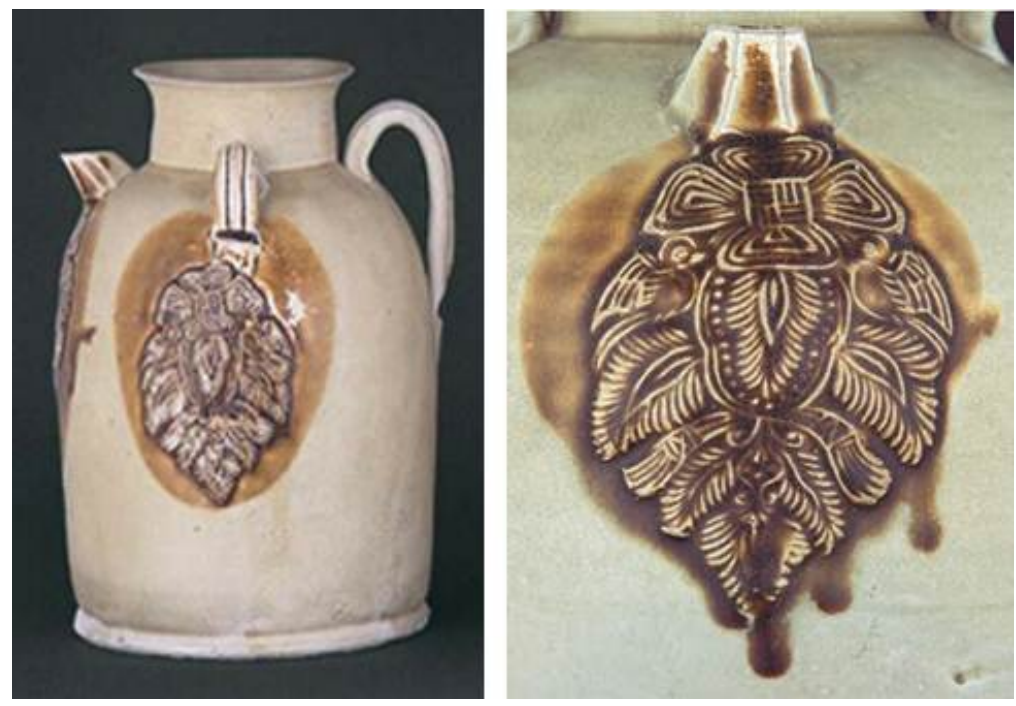

Figure 4. Changsha kiln wares with detail (Krahl, 2001)

The other question we would like to answer in this article is why the works of both regions are different particularly in ornamental forms, in spite of the reasons discussed and presented for the trading and artistic connections. To answer this question, three reasons could be discussed:

Based on the number of the discovered works in the wrecks of the sunken ship (as only one of many trading shipments of the Changsha ceramics), it can be estimated that the quantity of the works produced in Changsha was higher compared to those of Neyshabur's during its climax. This vast quantity led into a rapid process of production (a kind of production line). Such process needed forms and styles of rapid and linear transferring methods (ornamental forms) and this justifies the ornamental forms of many of Changsha works. This fast procedure was paradoxical for Neyshabur's works, specifically the plates with Kufi ornaments which required a very slow, time-consuming process (classes 3,4,5,8 of Wilkinson's categorization). 


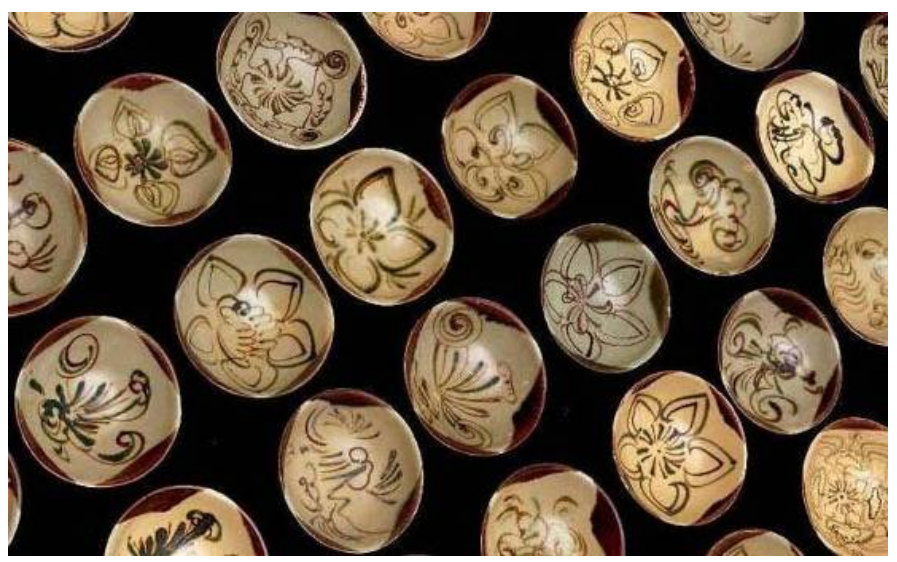

Figure 5. Changsha ceramic ornaments (Krahl, 2011)
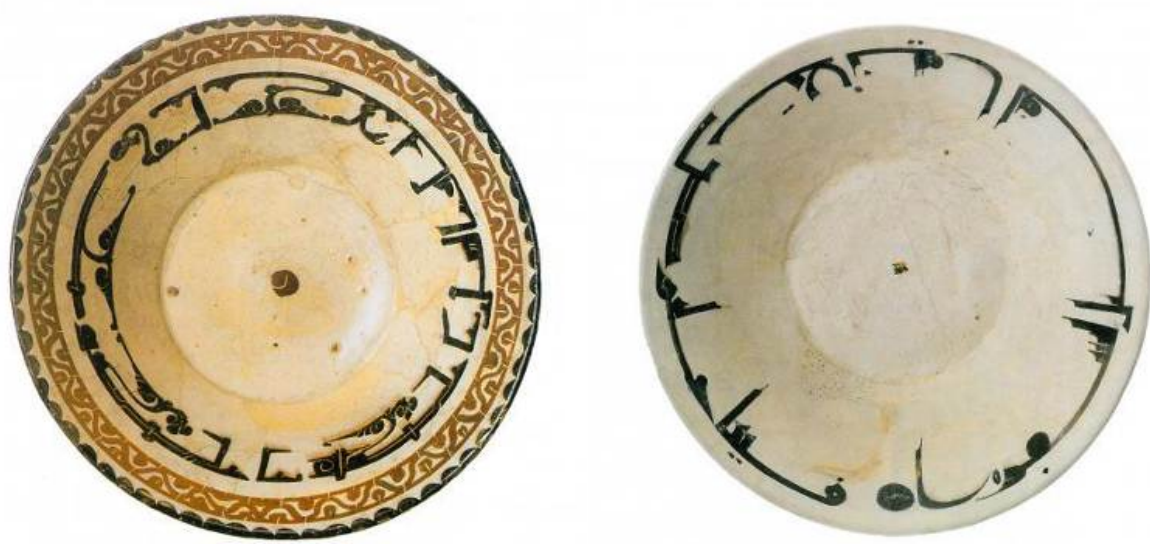

Figures 6 - 7. Neyshabur ceramic ornaments (Ghouchani, 1986)

In spite of the common ornamental themes such as plants, birds and animals in the ceramic ornament of both regions, the differences of visual patterns inevitably stands out in both cultures (Towhidi, 1999). For instance, there is an emphasis on the dynamism and simple figures in ornamental forms of Changsha, and on the contrary, a static mode along with a balance in the positive and negative phase is considered in the products of Neyshabur (Pope, 2001; Kinnier, 1813).

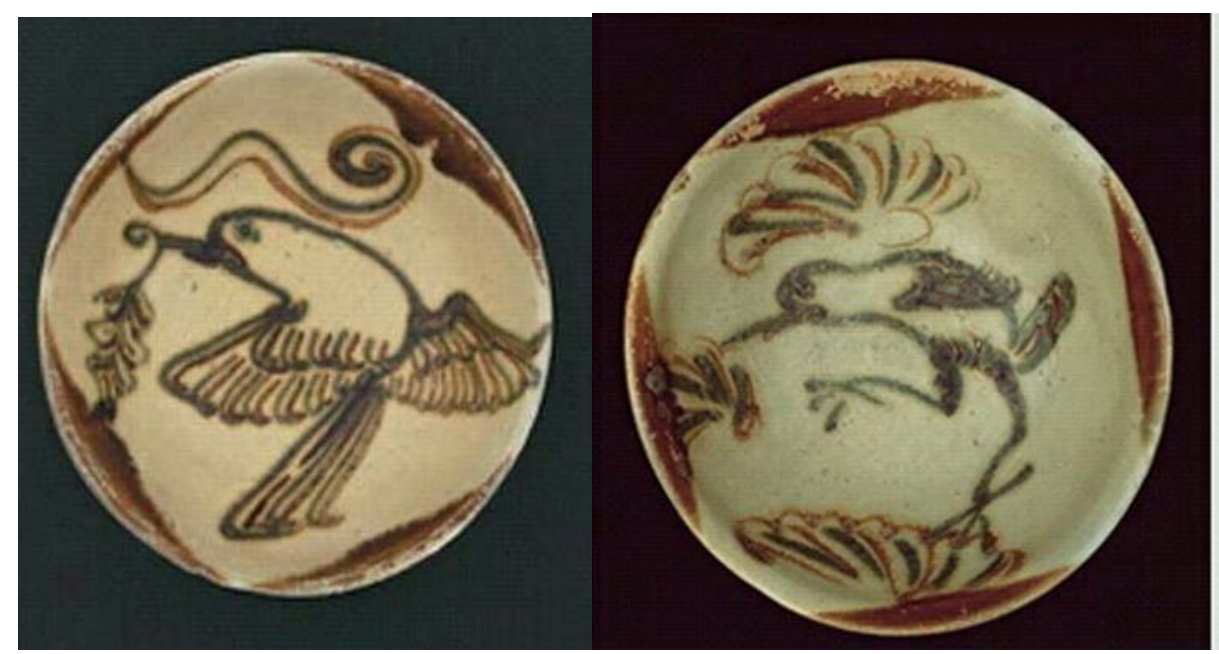

Figures 8 - 9. Changsha ceramic ornaments (Krahl, 2011) 

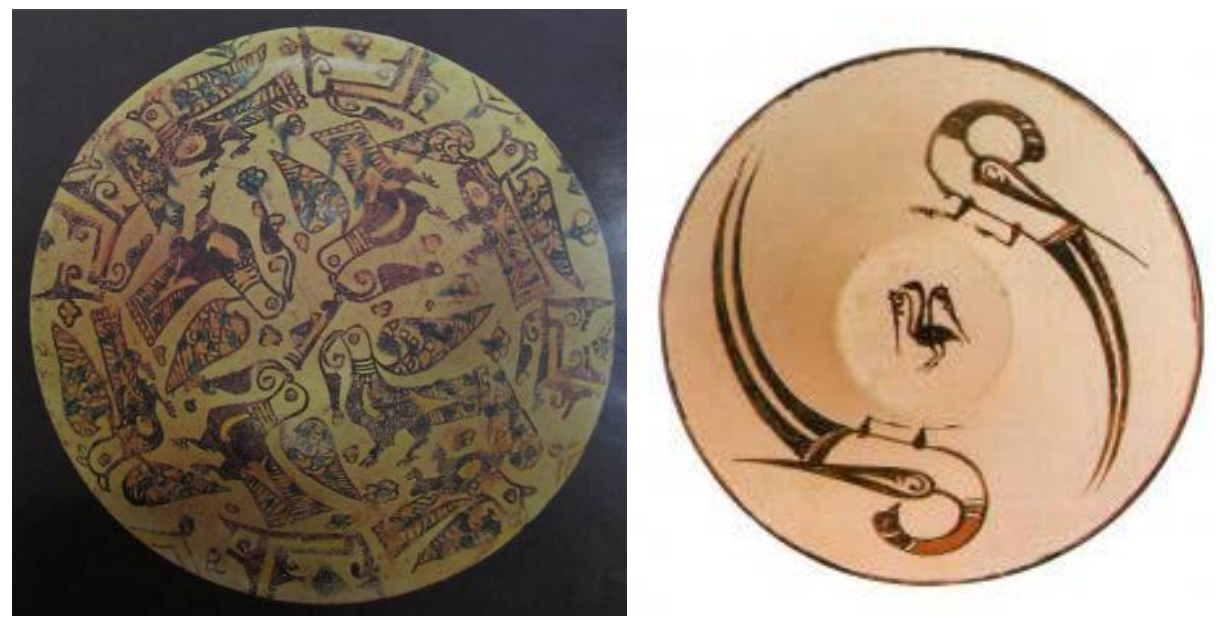

Figures 10 -11. Neyshabur ceramic ornaments (Rafii, 1999)

Studying the themes of the Neyshabur ornaments, the ones with calligraphy in particular, proves the close relation of the producer and the orderer. We could conclude, therefore, that many of manufactories of Neyshabur had local customers, and the local producers had a precise knowledge of their consumers' aesthetic and economic demands and their consuming methods (Ghouchani, 1986: 5-6). Yet such relation could not be concluded about Changsha due to its ultra-regional trade of ceramic products. This is perhaps the reason for the more specific forms of Neyshabur products and the more general forms of Changsha products.

\section{Conclusion}

Neyshabur ceramics were (mostly technically) influenced by the eastern methods, especially China's; in forms, ornament and dominant school of thought, they were inspired by and dependent upon the tradition of Iran and Islamic capitals. Considering the information given in this article, these reasons can be mentioned for the impact of Changsha products on Neyshabur's: discovered Changsha products in Neyshabur, technical and ornamental similarities in both regions (especially in 2,6,7,9 classes of the Wilkinson's categorization of Neyshabur products), the underglaze ornaments in Neyshabur which were among routine methods of decoration in Changsha which had no prior occurrence in Iran, applying calligraphy as an ornamental method in Changsha that was not been common previously in Iran. Nevertheless, the following reasons could be brought up for the differences of the products in the two regions:

- Differences in visual and cultural patterns between Iran and China.

- Distinct production procedure in manufactories of Iran and Neyshabur.

- Differences in the type of the relation between the customer and the producer in the regions.

All these reasons might prove the hypothesis that many craftsmen in Neyshabur were aware of the characteristics of the Changsha kiln products; with regard to the type and quantity of the order, some of them used this knowledge to produce some of their works.

Study of the social institutions of the producing societies, along with the semio-analysis of the calligraphic motifs used in the decorations of the artefacts and their similarities, might be the theme for further studies based on the present findings. 


\section{References}

Bulliet, R. W. (1973). The Patricians of Nishapur: A Study in Medieval Islamic Social History. Cambridge: Harvard University.

Chakanagi, A.; Zanganah, I.; Fadaee, S. A. \& Morvarid, M. (1996). The Silk Road, Translated by The Translation Department the Islamic Research Foundation Layout, by R. Ferdowsi. Mashhad: A. Q. R.

Ettinghausen, R. \& Yar-Shater, E. (Eds.). (1981). Highlights of Persian art (No. 1). Wittenborn Art Books.

Ghouchani, A. (1986). Inscription on Nishabur Pottery. Tehran: Reza Abbasi Museum.

Hasan, Z. (2005). China and the Arts of Islam. Tehran: Academy of Arts.

Kambakhsh, S. (2001). Ceramics and pottering. Tehran: Shemshad.

Karimi, F. \& Kiani, M. (1985). Pottery art of Iranian Islamic period. Tehran: Official culture and teaching ministry.

Kinnier, J. (1813). A Geographical Memoir of Persian Empire. London.

Krahl, R.; Guy, J.; Wilson, J. K. \& Raby, J. (2011). Shipwrecked: Tang Treasures and Monsoon Winds. Washington: Sackler Gallery.

Pope, A.u. (2001). Masterpieces of Persian art, Translated by Parviz Natel Khanlary. Tehran: Elmi Farhangi.

Rafii, L. (1999). Persian Pottery. Tehran: Yassavoli publications.

Towhidi, F. (1999). Pottery Technique and Art. Tehran: Samt.

Wikipedia (2017). Chinese Influences on Islamic Pottery. Tang Dynasty earthenware fragment with sancai glaze, end of 7th-early 8th century, excavated in Nishapur, Iran. http://en.wikipedia.org/wiki/Chinese_influences_on_Islamic_pottery

Wilkinson, C. (1973). Nishapur: pottery of the early Islamic period. New York: Metropolitan Museum of Art.

Wood, F. (2002). The Silk Road: Two Thousands Year in The Heart of Asia. Berkeley: University of California.

Worrall, S. (2009). Made in China: A 1.200 year old shipwreck opens a window on ancient global trade. National Geographic. https://www.nationalgeographic.com/magazine/2009/06/tang-shipwreck

Yang. L. (2011). Tang Dynasty Changsha Ceramics. In Shipwrecked: Tang Treasures and Monsoon Winds. R. Krahl, J. Guy, J. K. Wilson and J. Raby (Eds.), (pp. 144-159). Washington: Sackler Gallery. 